\title{
Proteolytically-cleaved Fragments of Cell Surface Proteins Stimulate a Cytotoxic Immune Response Against Tumor- activated Endothelial Cells In vitro
}

\author{
Elena E. Balashova ${ }^{1,3}$ and Petr G. Lokhov ${ }^{2,3 *}$ \\ ${ }^{1}$ Cardiology Research Center, Moscow, Russia \\ 2Institute of Biomedical Chemistry RAMS, Moscow, Russia \\ ${ }^{3} \mathrm{ZAO}$ BioBohemia, Moscow, Russia
}

\begin{abstract}
Endothelial antigens that stimulate immune-mediated damage of tumor vessels represent possible targets for the development of antiangiogenic vaccines aimed at preventing the progression of solid tumors. Since antigens expressed on the cell surface are accessible targets for both humoral and cell-mediated immune responses, the ability to isolate extracellular protein fragments from endothelial cells by proteolytic digest is a proposed strategy for the creation of antiangiogenic vaccines. Human microvascular endothelial cells (HMEC) were isolated from an abdominal subcutaneous adipose tissue biopsy. Both non-activated endothelial cells (nHMEC) and tumor-activated endothelial cells (aHMEC) were obtained. HMEC lysate and cleaved fragments of cell surface proteins (FCSP) of HMEC had total protein concentrations of $135 \mu \mathrm{g} / \mathrm{mL}$ and $2 \mu \mathrm{g} / \mathrm{mL}$, respectively. Despite this difference in concentration, FCSP were able to stimulate immune cells in cytotoxicity assays better than the HMEC lysate. Moreover, FCSP obtained from tumor-activated endothelial cells were able to stimulate an immune response toward tumor-activated endothelial cells. Based on these results, FCSP of endothelial cells appear to provide a comprehensive set of surface antigens that are able to induce targeted, immune-mediated cytotoxic effects against tumor endothelial cells. These findings represent a successful strategy to produce safe and pure antigens for the production of antiangiogenic vaccines.
\end{abstract}

Keywords: Antiangiogenic cancer vaccine; Tumor-associated antigens; Endothelial cells Abbreviations: DC: Dendritic Cells; PBMC: Peripheral Blood
Mononuclear Cells; CTL: Cytotoxic T Lymphocytes; HMEC: Human
Microvascular Endothelial Cells; nHMEC: Non-Activated Endothelial
Cells; aHMEC: Tumor-activated Endothelial Cells; FCSP: Fragments
of Cell Surface Proteins

\section{Introduction}

The secretion of angiogenic stimulators by malignant cells activates endothelial cells to proliferate and form new blood vessels, and this additional vascular capacity is essential for tumor growth and metastasis (Carmeliet and Jain, 2000; Ellis and Fidler, 1996; Folkman, 1971; Folkman, 1990; Liotta et al., 1991; Pluda, 1997; Pralhad et al., 2003). The expression of antigens associated with tumor-stimulated angiogenesis represents distinguishing traits of angiogenic endothelial cells versus endothelium of the normal vasculature (Bhati et al., 2008; Khodarev et al., 2003; St Croix et al., 2000). Various approaches have been used to target angiogenic vasculature, including monoclonal antibodies and synthetic molecules, which have been shown to inhibit tumor growth in animal models and have been administered in clinical trials (Arap et al., 1998; Folkman, 2007; Liao et al., 2002; Scappaticci, 2002; Schraa et al., 2002; Shaheen et al., 2001). However, these antiangiogenesis therapies can be expensive if a high dose and extended administration period is needed to compensate for a short half-life of these therapeutics. In addition, antigens highly specific for angiogenic endothelium remain elusive. An active immunization with endothelial cells overcomes these limitations. This vaccination approach offers the advantage that targeting of autologous antigens and previously uncharacterized antigens can be achieved without needing to isolate the relevant targets. Previously this approach has been shown to inhibit the growth of experimental tumors in mouse models (Chen et al., 2006; Corsini et al., 2004; Okaji et al., 2004; Okaji et al., 2006; Scappaticci and Nolan, 2003; Wei et al., 2000). However, there are additional considerations to this approach. For example, while whole cells provide surface antigens that induce a desired immune response, they also contain a high abundance of housekeeping proteins, carbohydrates, nucleic acids, and other intracellular contents that are commonly expressed by all mammalian cells. These ubiquitous molecules would be undesirable targets for an immune response, and represent a possible reason for the failure of cell-based vaccines (Cohen et al., 2009; Copier and Dalgleish, 2010). Another potential limitation of cell-based vaccines includes the difficulty associated with purifying cells from intracellular contaminants such as cell parasites, viruses, toxins, and prions. Successful purification would be essential for the administration of anti-cancer vaccines (Emens, 2006; Levine and Sztein, 2004).

One potential approach to the production of antiangiogenic vaccines is to isolate essential targets localized to the endothelial cell surface. Since the immune response is usually based on the recognition of extracellular cell surface molecules, proteins, and glycoproteins, proteolytic cleavage represents the ability to isolate these protein groups from the cell surface. While the antigen profile obtained by proteolytic cleavage would contain a comprehensive

*Corresponding author: Dr. Petr G. Lokhov, Institute of Biomedical Chemistry RAMS, Moscow, Russia, Tel: +7 90374451 91; Fax: +7 49514322 77; E-mail: lokhovpg@rambler.ru

Received June 15, 2010; Accepted August 04, 2010; Published August 04, 2010

Citation: Balashova EE, Lokhov PG (2010) Proteolytically-cleaved Fragments of Cell Surface Proteins Stimulate a Cytotoxic Immune Response Against Tumoractivated Endothelial Cells In vitro. J Cancer Sci Ther 2: 126-131. doi:10.4172/19485956.1000037

Copyright: @ 2010 Balashova EE, et al. This is an open-access article distributed under the terms of the Creative Commons Attribution License, which permits unrestricted use, distribution, and reproduction in any medium, provided the original author and source are credited. 
set of native antigens, the immune system could be directed to recognize a subset of these antigens that do not represent ubiquitous molecules presented in all normal cells. Therefore, this study investigates the ability of a trypsin treatment to proteolytically cleave the cell surface antigens of human microvascular endothelial cells (HMEC), and the use of these cleaved protein fragments to stimulate immune-mediated cytotoxic responses against tumoractivated HMEC in vitro.

\section{Materials and Methods}

\section{Primary culture of HMEC}

An abdominal subcutaneous adipose tissue biopsy was obtained from a male patient undergoing an open-abdominal surgical procedure at the National Medico-Surgical Center (Moscow, Russia). The protocol was approved by the Research Ethics Committee and the patient provided his written informed consent. The biopsy specimen was transported to the laboratory in Ringer solution (transport time $45 \mathrm{~min}$ ), and after removal of the visible fibrous tissue, the fat was finely minced and incubated for $45 \mathrm{~h}$ at $37^{\circ} \mathrm{C}$ in digest solution $(0.5 \mathrm{mg} / \mathrm{ml}$ collagenase IA (Sigma-Aldrich, USA) prepared with Hank's Balanced Salt Solution (HBSS)) at a ratio of 4:1 (v/v) (Hutley et al., 2001). The digested material was then intensely shaken for $2 \mathrm{~min}$ then centrifuged $(300 \times g$ for $10 \mathrm{~min})$ to separate adipocytes and free oil from the stromovascular components. The stromovascular pellet was resuspended in HBSS and washed $3 \mathrm{x}$ by centrifugation $(600 \times g$ for $5 \mathrm{~min})$. The resulting pellet was incubated in $0.25 \%$ trypsin (activity $300 \mathrm{U} / \mathrm{mg}$, PanEco, Russia) containing $1 \mathrm{mM}$ EDTA for $15 \mathrm{~min}$ at RT, followed by 3 washes with PBS containing $0.1 \%$ bovine serum albumin (BSA) by centrifugation $(600 \times g$ for $5 \mathrm{~min})$. Endothelial cells were isolated using CD31 Dynabeads (Invitrogen, USA) according to the manufacturer's protocol, and seeded onto $1 \%$ gelatin-coated 6-well tissue culture plates in selective endothelial cell growth medium (DMEM with D-valine (PanEco, Russia), 20\% fetal bovine serum (PAA Laboratories, USA), $100 \mathrm{U}$ penicillin, $100 \mu \mathrm{g} / \mathrm{ml}$ streptomycin, $2 \mathrm{mM}$ L-glutamine, $12 \mathrm{U} / \mathrm{ml}$ heparine, $50 \mu \mathrm{g} / \mathrm{ml}$ endothelial cell growth supplement from bovine pituitary (Sigma-Aldrich)) at $37^{\circ} \mathrm{C}$ in $7.5 \% \mathrm{CO}_{2}$. Culture media was changed every 2-3 days and after the first passage, cells were grown to $75 \%$ confluence and used in further experiments as non-activated endothelial cells (nHMEC). To obtain tumor-activated endothelial cells (aHMEC), cell cultures were incubated for 2 days in medium collected from MCF-7 human breast adenocarcinoma cells (ATCC, Manassas, VA) as described by Folkman et al. (1979). Briefly, growth medium was aspirated and replaced with the medium to be conditioned. After $48 \mathrm{~h}$, the medium was collected, centrifuged for $10 \mathrm{~min}$ at $600 \mathrm{xg}$, filter sterilized $(0.2 \mu \mathrm{m})$, and added to cultures.

\section{Preparation of FCSP from HMEC}

HMEC grown to $75 \%$ confluence were washed $5 \times$ with HBSS before being treated with $0.2 \mu \mathrm{g} / \mathrm{mL}$ trypsin $(15000 \mathrm{U} / \mathrm{mg}$, Promega, Madison, WI) in HBSS. One $\mathrm{mL}$ of trypsin solution was added to each $25 \mathrm{~cm}^{2}$ flask, incubated for $20 \mathrm{~min}$ at $37^{\circ} \mathrm{C}$ in saturated humidity, then collected again and centrifuged $(600 \times g$ for $5 \mathrm{~min})$. The resulting supernatant contained fragments of cell surface proteins (FCSP) from HMEC, and total protein concentration for this FCSP preparation was determined using a $\mathrm{BCA}^{\mathrm{TM}}$ Protein Assay Kit (Thermo Scientific, USA).

Cell growth medium containing 20\% FCS was added to the treated HMEC and cell viability was determined directly in flask using the trypan blue exclusion method (Hudson and Hay, 1980). Viability of cells that became detached during trypsin digestion was also taken into account. The number of viable cells present was calculated by subtracting an average number of cells stained with trypan blue from the average number of cells observed in 5 separate fields.

\section{Preparation of HMEC lysate}

HMEC grown to $75 \%$ confluence in $25 \mathrm{~cm}^{2}$ flasks were washed $5 \mathrm{x}$ with HBSS then detached with a cell scraper in $1 \mathrm{~mL}$ HBSS. Collected cells were freeze-thawed three times (Nestle et al., 1998) then centrifuged for $5 \mathrm{~min}$ at $600 \times \mathrm{g}$. Protein concentrations were determined using a $\mathrm{BCA}^{\mathrm{TM}}$ Protein Assay Kit and supernatants were used to load DC.

\section{Preparation of cell lysate- and FCSP-loaded DC}

Monocyte-derived DC were generated as described previously (Romani et al., 1994). Briefly, fresh peripheral blood mononuclear cells (PBMC) from healthy donors were isolated using Ficoll-Hypaque (PanEco, Russia) gradient centrifugation and were then allowed to adhere to culture flasks for $1 \mathrm{~h}$. Non-adherent cells were collected and centrifuged, and cell pellets were mixed with autologous serum containing 10\% DMSO and stored in liquid nitrogen. Cryopreserved, non-adherent PBMC were later used as a source of effector cells (cytotoxic T lymphocytes, CTL) for cytotoxicity assays. The adherent cell fraction was cultured in RPMI-1640 (PanEco) supplemented with $10 \% \mathrm{FBS}$ (PAA Laboratories) in the presence of $1000 \mathrm{U} / \mathrm{mL}$ granulocyte macrophage colony-stimulating factor (Sigma-Aldrich) and $1000 \mathrm{U} /$ $\mathrm{mL}$ interleukin-4 (Sigma-Aldrich). After $6 \mathrm{~d}$ in culture, either HMEC lysate $(250 \mu \mathrm{g} / \mathrm{mL}, 1 \mathrm{~mL})$ or FCSP $(3 \mu \mathrm{g} / \mathrm{mL}, 1 \mathrm{~mL})$ were combined with an equal volume $(1 \mathrm{~mL})$ of immature DC. Antigen loading was allowed to occur for $3 \mathrm{~h}$, then DC were matured with $1000 \mathrm{U} / \mathrm{mL}$ tumor necrosis factor- $\alpha$ (Sigma-Aldrich) for $48 \mathrm{~h}$. Matured, lysate- or FCSP-loaded DC were then used to stimulate CTL. For successive cycles of CTL stimulation, aliquots of matured and loaded DC were cryopreserved and thawed as needed. The freezing method used has been previously described (John et al., 2005).

\section{Stimulation of CTL}

Lysate- or FCSP-loaded DC $\left(4.5 \times 10^{4}\right)$ were washed with HBSS and cultured in 6-well plates. DC were combined with $9 \times 10^{5}$ autologous non-adherent PBMC (1:20) in $4 \mathrm{~mL}$ of RPMI-1640 medium supplemented with $30 \mathrm{U} / \mathrm{mL}$ clinical grade human interleukin-2 (Ronkoleukin, Russia) and 10\% FBS, and this medium was replaced every third day. The second portion of antigen-loaded DC was added to PBMC $7 \mathrm{~d}$ after stimulation. After another $5 \mathrm{~d}$, non-adherent PBMC containing stimulated CTL were washed by centrifugation and used in cytotoxicity assays as effector cells.

\section{Cytotoxicity assays}

HMEC $\left(2 \times 10^{4}\right.$ cells/well $)$ were seeded into 48 -well plates, which yielded $3.7 \times 10^{4}$ cells/well after $48 \mathrm{~h}$. Effector CTL were then added to HMEC at an effector: target ratio of $8: 1$. On the $3^{\text {rd }}$ day, target HMEC were washed to remove CTL and were photographed using an inverted phase contrast microscope. In duplicate wells, attached HMEC were trypsinized and viability was detected using trypan blue exclusion. Cell counts were averaged over three measurements and the number of HMEC in the absence of effector CTL, as well as with CTL that had been stimulated with unloaded DC, were used as controls. Statistically significant differences were determined using Student's t-test. 

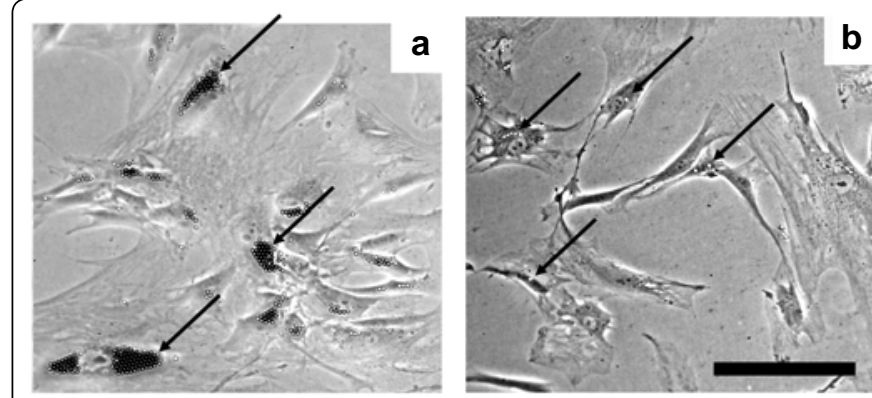

Figure 1: Primary culture of human microvascular endothelial cells (HMEC) A representative colony of microvascular endothelial cells associated with anti-CD31 beads $24 \mathrm{~h}$ after isolation (a), and after the first passage (b). There were no cells not associated with CD31 beads that would represent contaminating cells. Images were obtained using an inverted phase contrast microscope (scale bar: $50 \mu \mathrm{m}$ ). Arrows show beads attached to cells.

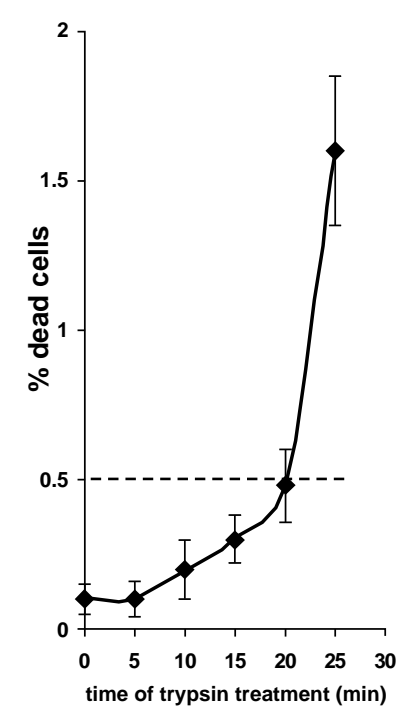

Figure 2: HMEC viability following treatment with trypsin. In situ trypan blue staining of endothelial cell cultures at various timepoints during treatment with $0.2 \mu \mathrm{g} / \mathrm{mL}$ trypsin (activity $1500 \mathrm{U} / \mathrm{mg}$ ). The percentage of dead cells were calculated as the average number of stained cells \pm SD per field with the result from each of the five fields being averaged. The dotted line shows percent of dead cells corresponding to time which has been selected for obtaining of FCSP.

\section{Results}

\section{Primary culture of HMEC}

To isolate micro vascular endothelial cells from a biopsy of abdominal fat obtained, anti-CD31 beads were used as described in the Materials and methods. Figure 1a shows a colony of endothelial cells isolated after $24 \mathrm{~h}$ with numerous beads still attached to the isolated cells. After $7 \mathrm{~d}$, the endothelial cells isolated formed a confluent monolayer, with the number of beads bound per cell decreasing with each replication cycle. As shown in Figure 1b, beads were still attached to endothelial cells when the first passaging following isolation was performed, yet no evidence of overgrowth by contaminating cells was detected. Thus, a primary culture of HMEC was established.

\section{Preparation of FCSP}

To select conditions optimal for the cleavage of extracellular proteins from HMEC, in situ trypan blue staining of HMEC was used to assay the cell death rate following treatment with a $2 \times 10^{-50}$ \% solution of highly purified (activity $15000 \mathrm{U} / \mathrm{mg}$ ) trypsin. The cell death rate did not exceed $0.5 \%$ after incubation of the HMEC with trypsin for $20 \mathrm{~min}$, therefore, these conditions were selected for the preparation FCSP. The total protein concentration for preparations of FCSP vs. HMEC lysates was $2 \mu \mathrm{g} / \mathrm{mL}$ vs. $135 \mu \mathrm{g} / \mathrm{mL}$, respectively.

\section{Cytotoxicity assays}

The immunologic properties of the FCSP were also evaluated by loading DC with the digested material and stimulating normal human cytotoxic T lymphocytes (CTL). In these cytotoxicity assays, unloaded DC were used as controls and lysate-loaded DC were used as reference DC. CTL stimulated with FCSP-loaded DC were observed to kill target HMEC as effectively as CTL stimulated with lysate-loaded DC. Similar observations were made for nonactivated and activated HMEC used as target cells (Figure 3, c-f \& c'-f', respectively).

On day 3, surviving endothelial cells were detected using trypan blue exclusion (Figure 4) and a slight increase in cytotoxic activity was observed when CTL stimulated with unloaded DC were incubated with target HMEC (Figure $4 \mathrm{~b}, \mathrm{~b}$ ). CTL stimulated with DC loaded with FCSP were more effective than CTL stimulated with DC loaded with lysate in killing target HMEC at each assay point (Figure 4, c vs. e, d vs. f, c' vs. e', and d' vs. f'; $\mathrm{p}<0.05$ for d' vs. f'). Furthermore, DC loaded with FCSP prepared from activated endothelial cells resulted in more effective killing activated than non-activated target endothelial cells (Figure 4 e' vs. f', $p<0.01$ ). Similar results were obtained when DC loaded with FCSP prepared from non-activated endothelial cells toward activated or nonactivated targeted endothelial cells, and killing was more effective in the latter case (Figure 4 e vs. f, $p<0.05$ ).

\section{Discussion}

Many studies have shown that cancer cells can provide a comprehensive set of native antigens suitable for inducing an immune response (Chiang et al., 2010; de Gruijl et al., 2008; Thompson and Dessureault, 2007), therefore, a similar approach has been proposed for the use of endothelial cells to develop antiangiogenic, anti-cancer vaccines. However, numerous shortcomings have been associated with the use of whole endothelial cells. For example, while endothelial cells provide the extracellular macromolecules, which are accessible to antibodies and cytotoxic cells of the immune system, they also include intracellular substances which are ubiquitous in all mammalian cells, including normal endothelial cells (Cohen et al., 2009). Another crucial shortcoming is the possible presence of cell parasites, viruses, toxins, or prions in cells, which would make the administration of any whole cell preparations dangerous. Therefore, an approach which allows a subset of extracellular antigens to be isolated and used to develop vaccines is needed.

In this study, cell surface antigens were obtained from primary culture of HMEC. By carefully manipulating the cells and using a highly purified protease, antigenic targets present on the cell surface, referred to as FCSP, were isolated. The decision to use HMEC in these assays was based on previous characterizations of endothelial cells involved in tumor angiogenesis which predominantly identified endothelial cells of micro vascular origin. In addition, micro vascular endothelial cells exhibit a number of functional differences compared to large vessel-derived endothelial 
Citation: Balashova EE, Lokhov PG (2010) Proteolytically-cleaved Fragments of Cell Surface Proteins Stimulate a Cytotoxic Immune Response Against Tumor-activated Endothelial Cells In vitro. J Cancer Sci Ther 2: 126-131. doi:10.4172/1948-5956.1000037

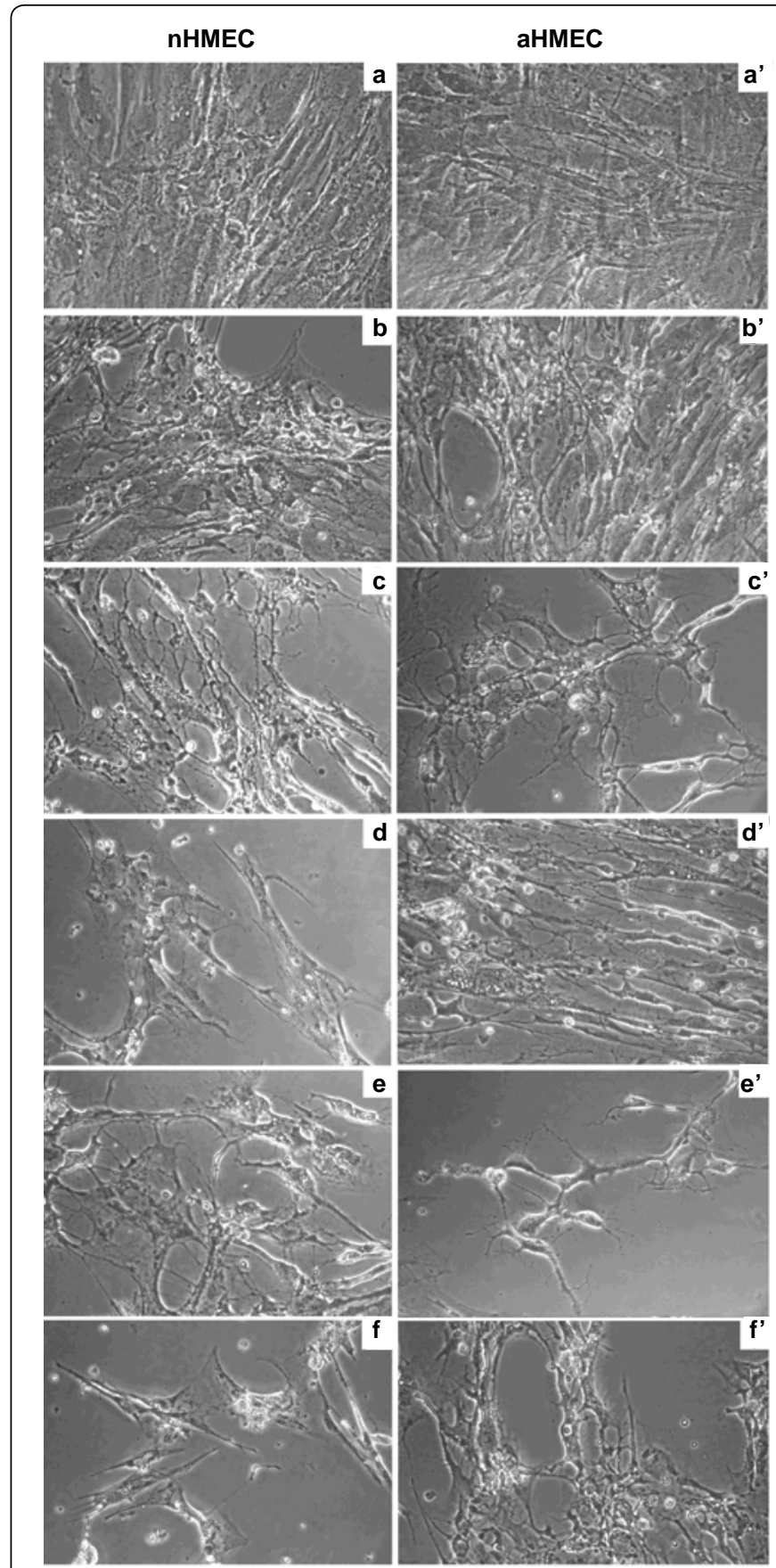

Figure 3: CTL-mediated lysis of HMEC in cytotoxicity assays. Nonactivated HMEC (nHMEC) and tumor-conditioned medium activated HMEC (aHMEC) $\left(3.7 \times 10^{4}\right.$ cells/well) were incubated with effector CTL at a ratio of $1: 8$ and were imaged using an inverted phase contrast microscope. Untreated nHMEC and aHMEC (a, a') are compared with nHMEC and aHMEC incubated with: CTL stimulated with control (unloaded with antigens) DC (b, b'), CTL stimulated with DC loaded with aHMEC lysate (c, c'), CTL stimulated with DC loaded with nHMEC lysate (d, d'), CTL stimulated with DC loaded with FCSP prepared from aHMEC (e, e'), and CTL stimulated with DC loaded with FCSP prepared from nHMEC (f, f'). For panels a-f, nHMEC are the target cells, and in panels a'-f', aHMEC are the target cells.

cells (Kumar et al., 1987; Lang et al., 2003), including their response to stimulators (Hewett, 2001; Shreeniwas et al., 1991) and their regulation of extracellular protein expression (Lee et al., 1992; Swerlick et al., 1992a; Swerlick et al., 1992b). Although the isolation

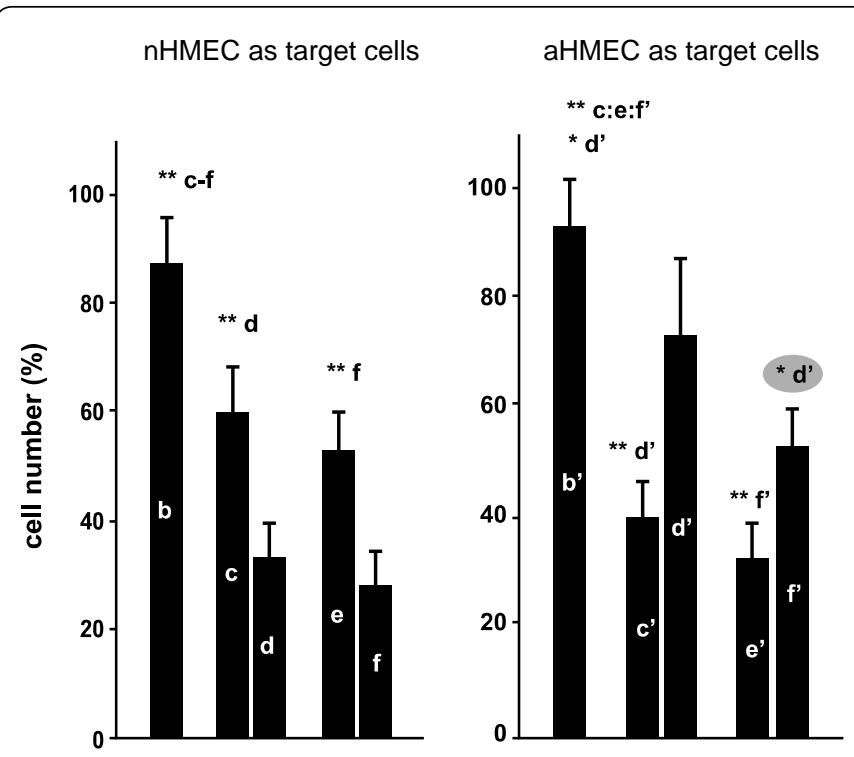

Figure 4: Cytotoxicity of effector CTL against HMEC. Target HMEC cells $\left(3.7 \times 10^{4}\right.$ cells/well) were incubated with effector CTL at a ratio of 1:8. After 3 days, floating CTL were removed, target cells were carefully washed with HBSS, and attached HMEC were trypsinized and cell viability determined. Bars correspond to images in Figure 4 according to literal notation. The number of calculated HMEC present in control cultures was set as $100 \%$. ${ }^{* *}-p<0.01 ;{ }^{*}-p<0.05$, additional marks indicate bars paired to calculate $p$. Data represent the mean value of 3 identical measurements \pm SD.

and culture of micro vascular endothelial cells is difficult due to the potential for contamination from other cell types, including mesothelial cells (Hewett et al., 1993; Hull et al., 1996; Potzsch et al., 1990), the use of magnetic beads coated with anti-CD31 antibodies was shown in this study to address this problem since HMEC were the predominant population expressing CD31 (Figure 1), which is consistent with the results of other studies (Hewett and Murray, 1994; Hull et al., 1996).

The use of proteases to isolate a subset of cell surface antigens for anti angiogenesis vaccines is only useful if the treatment with proteases is associated with a low rate of cell death. This is necessary to avoid the contamination of the isolated extracellular antigens with the intracellular contents released from dead cells. In this study, a cell death rate of less than $0.5 \%$ was achieved following treatment with trypsin (Figure 2). Moreover, the protein content of the FCSP preparations was found to be $2 \mu \mathrm{g} / \mathrm{mL}$, which was significantly lower than the protein content of HMEC lysates $(135 \mu \mathrm{g} /$ $\mathrm{mL})$. This difference in the concentration of antigens detected is due to the presence of both extracellular and intracellular proteins in the HMEC lysates, while the FCSP preparations only contain proteins that were cleaved from the cell surface. This is consistent with data reported in a previous study where $\sim 5 \mu \mathrm{g}$ of protein was isolated from the plasma membrane of $1 \times 10^{6}$ mammalian cells (Deblaquiere and Burgess, 1999).

To confirm that the FCSP contained essential antigens for vaccination, the immunogenic properties of both FCSP preparations and cell lysates were compared. Using an in vitro model of human antiangiogenic therapies where human CTL were incubated with endothelial cell targets, DC loaded with FCSP were found to stimulate the cytotoxic actions of CTL just as effectively as DC loaded with lysates (Figure 4). Therefore, despite the much lower concentration of total protein associated with the FCSP 
preparations, the same ability to induce cytotoxic activity in CTL indicated that the necessary antigens were present in the absence of intracellular proteins. Correspondingly, this proof-of-concept study demonstrated that the treatment of endothelial cells with trypsin can release antigenic targets that are sufficient to induce antiangiogenic, antitumor immune responses in vitro.

Endothelial cells in tumors that are stimulated to proliferate in response to tumor-secreted stimulators, undergo changes that make them distinct from endothelial cells of the normal vasculature, particularly in regard to expression of cell surface macromolecules (Ruoslahti and Rajotte, 2000; St Croix et al., 2000). By performing cytotoxicity assays with tumor-activated HMEC as the target cells, the capacity for the treatment of HMEC with trypsin to provide antigens for the stimulation of the immune response specifically for tumor endothelial cells was demonstrated. Similarly, activation of endothelial cells by tumor-conditioned medium has previously been shown to be a widely accepted in vitro model of tumor-activated endothelial cells (Folkman and Haudenschild, 1980; Folkman et al., 1979; Li et al., 2003; Papetti and Herman, 2002).

CTL stimulated with DC loaded with FCSP obtained from activated endothelial cells were associated with a greater cytotoxicity than non-activated HMEC. Moreover, CTL stimulated with DC loaded with FCSP vs. lysates obtained from non-activated endothelial cells were more cytotoxic, respectively, toward non-activated HMEC. These results suggest that FCSP of tumoractivated HMEC contain the relevant antigens to stimulate the immune response toward tumor endothelial cells. In particular, it is remarkable that FCSP stimulated the immune response better than lysates, and when aHMEC were used as the target cells, the stimulation by FCSP was statistically significant (see ellipse mark in Figure 4). We hypothesize that this is due to the absence of intracellular substances in the FCSP preparations which would otherwise interfere with target antigens during the loading of DC, thereby leading to a less targeted immune response.

\section{Conclusions}

While additional studies are need to identify the optimal choice of adjuvant and administration schedule for vaccine development, the diversity of native endothelial-associated antigens obtained, the low levels of undesirable antigens present, and the strong immune response stimulated, are all factors that demonstrate the potential for FCSP to provide antiangiogenic, anti-cancer vaccines.

\section{Acknowledgements}

We would like to thank Dr. Kira F. Kim (National Medico-Surgical Center, Moscow, Russia) for kindly provided sample of adipose tissue biopsy, and ZAO BioBohemia (Moscow, Russia) for financial support.

\section{References}

1. Arap W, Pasqualini R, Ruoslahti E (1998) Cancer treatment by targeted drug delivery to tumor vasculature in a mouse model. Science 279: 377-380.

2. Bhati R, Patterson C, Livasy CA, Fan C, Ketelsen D, et al. (2008) Molecular characterization of human breast tumor vascular cells. Am J Pathol 172: $1381-1390$.

3. Carmeliet P, Jain RK (2000) Angiogenesis in cancer and other diseases. Nature 407: 249-257.

4. Chen XY, Zhang W, Wu S, Bi F, Su YJ, et al. (2006) Vaccination with viable human umbilical vein endothelial cells prevents metastatic tumors by attack on tumor vasculature with both cellular and humoral immunity. Clin Cancer Res 12: 5834-5840.

5. Chiang CL, Benencia F, Coukos G (2010) Whole tumor antigen vaccines. Semin Immunol 22: 132-143.
6. Cohen EP, Chopra A, O-Sullivan I, Kim TS (2009) Enhancing cellular cancer vaccines. Immunotherapy 1: 495-50.

7. Copier J, Dalgleish A (2010) Whole-cell vaccines: A failure or a success waiting to happen? Curr Opin Mol Ther 12: 14-20.

8. Corsini E, Gelati M, Calatozzolo C, Alessandri G, Frigerio S, et al. (2004) Immunotherapy with bovine aortic endothelial cells in subcutaneous and intracerebral glioma models in rats: effects on survival time, tumor growth, and tumor neovascularization. Cancer Immunol Immunother 53: 955-962.

9. de Gruijl TD, van den Eertwegh AJ, Pinedo HM, Scheper RJ (2008) Wholecell cancer vaccination: from autologous to allogeneic tumor- and dendritic cell-based vaccines. Cancer Immunol Immunother 57: 1569-1577.

10. Deblaquiere J, Burgess A (1999) Affinity purification of plasma membranes. J Biomol Tech 10: 64-71.

11. Ellis LM, Fidler IJ (1996) Angiogenesis and metastasis. Eur J Cancer 32 2451-2460.

12. Emens LA (2006) Roadmap to a better therapeutic tumor vaccine. Int Rev Immunol 25: 415-443.

13. Folkman J (1971) Tumor angiogenesis: therapeutic implications. $\mathrm{N}$ Engl J Med 285: 1182-1186.

14. Folkman $J(1990)$ What is the evidence that tumors are angiogenesis dependent? J Natl Cancer Inst 82: 4-6.

15. Folkman J (2007) Angiogenesis: an organizing principle for drug discovery? Nat Rev Drug Discov 6: 273-286.

16. Folkman J, Haudenschild C (1980) Angiogenesis in vitro. Nature 288: 551556.

17. Folkman J, Haudenschild CC, Zetter BR (1979) Long-term culture of capillary endothelial cells. Proc Natl Acad Sci U S A 76: 5217-5221.

18. Hewett PW (2001) Identification of tumour-induced changes in endothelial cell surface protein expression: an in vitro model. Int J Biochem Cell Biol 33: 325-335.

19. Hewett PW, Murray JC (1994) Human omental mesothelial cells: A simple method for isolation and discrimination from endothelial cells. In Vitro Cell Dev Biol 30: 145-147.

20. Hewett PW, Murray JC, Price EA, Watts ME, Woodcock M (1993) Isolation and characterization of microvessel endothelial cells from human mammary adipose tissue. In Vitro Cell Dev Biol Anim 29A: 325-331.

21. Hudson L, Hay FC (1980) Practical Immunology. Blackwell Scientific Publications, Oxford, 29-31.

22. Hull MA, Hewett PW, Brough JL, Hawkey CJ (1996) Isolation and culture of human gastric endothelial cells. Gastroenterology 111: 1230-1240.

23. Hutley LJ, Herington AC, Shurety W, Cheung C, Vesey DA, et al. (2001) Human adipose tissue endothelial cells promote preadipocyte proliferation. Am J Physiol Endocrinol Metab 281: E1037-E1044

24. John J, Dalgleish A, Melcher A, Pandha H (2005) Cryopreserved dendritic cells for intratumoral immunotherapy do not require re-culture prior to human vaccination. J Immunol Methods 299: 37-46.

25. Khodarev NN, Yu J, Labay E, Darga T, Brown CK, et al. (2003) Tumourendothelium interactions in co-culture: coordinated changes of gene expression profiles and phenotypic properties of endothelial cells. J Cell Sci 116: 1013-1022.

26. Kumar S, West DC, Ager A (1987) Heterogeneity in endothelial cells from large vessels and microvessels. Differentiation 36: 57-70.

27. Lang I, Pabst MA, Hiden U, Blaschitz A, Dohr G, et al. (2003) Heterogeneity of microvascular endothelial cells isolated from human term placenta and macrovascular umbilical vein endothelial cells. Eur J Cell Biol 82: 163-173.

28. Lee KH, Lawley TJ, Xu YL, Swerlick RA (1992) VCAM-1-, ELAM-1-, and ICAM-1-independent adhesion of melanoma cells to cultured human dermal microvascular endothelial cells. J Invest Dermatol 98: 79-85.

29. Levine MM, Sztein MB (2004) Vaccine development strategies for improving immunization: the role of modern immunology. Nat Immunol 5: 460-464.

30. Li A, Li H, Zhang J, Jin G, Xiu R (2003) The mitogenic and anti-apoptotic activity of tumor conditioned medium on endothelium. Clin Hemorheo Microcirc 29: 375-382. 
Citation: Balashova EE, Lokhov PG (2010) Proteolytically-cleaved Fragments of Cell Surface Proteins Stimulate a Cytotoxic Immune Response Against Tumor-activated Endothelial Cells In vitro. J Cancer Sci Ther 2: 126-131. doi:10.4172/1948-5956.1000037

31. Liao F, Doody JF, Overholser J, Finnerty B, Bassi R, et al. (2002) Selective targeting of angiogenic tumor vasculature by vascular endothelial-cadherin antibody inhibits tumor growth without affecting vascular permeability. Cancer Res 62: 2567-2575.

32. Liotta LA, Steeg PS, Stetler-Stevenson WG (1991) Cancer metastasis and angiogenesis: an imbalance of positive and negative regulation. Cell 64: 327 336

33. Nestle FO, Alijagic S, Gilliet M, Sun Y, Grabbe S, et al. (1998) Vaccination of melanoma patients with peptide- or tumor lysate-pulsed dendritic cells. Nat Med 4: 328-332.

34. Okaji Y, Tsuno NH, Kitayama J, Saito S, Takahashi T, et al. (2004) Vaccination with autologous endothelium inhibits angiogenesis and metastasis of colon cancer through autoimmunity. Cancer Sci 95: 85-90.

35. Okaji Y, Tsuno NH, Saito S, Yoneyama S, Tanaka M, et al. (2006) Vaccines targeting tumour angiogenesis--a novel strategy for cancer immunotherapy. Eur J Surg Oncol 32: 363-370.

36. Papetti M, Herman IM (2002) Mechanisms of normal and tumor-derived angiogenesis. Am J Physiol Cell Physiol 282: C947-C970.

37. Pluda JM (1997) Tumor-associated angiogenesis: mechanisms, clinical implications, and therapeutic strategies. Semin Oncol 24: 203-218.

38. Potzsch B, Grulich-Henn J, Rossing R, Wille D, Muller-Berghaus G (1990) Identification of endothelial and mesothelial cells in human omental tissue and in omentum-derived cultured cells by specific cell markers. Lab Invest 63: $841-852$

39. Pralhad T, Madhusudan S, Rajendrakumar K (2003) Concept, mechanisms and therapeutics of angiogenesis in cancer and other diseases. J Pharm Pharmacol 55: 1045-1053.

40. Romani N, Gruner S, Brang D, Kampgen E, Lenz A, et al. (1994) Proliferating dendritic cell progenitors in human blood. J Exp Med 180: 83-93.
41. Ruoslahti E, Rajotte D (2000) An address system in the vasculature of normal tissues and tumors. Annu Rev Immunol 18: 813-827.

42. Scappaticci FA (2002) Mechanisms and future directions for angiogenesisbased cancer therapies. J Clin Oncol 20: 3906-3927.

43. Scappaticci FA, Nolan GP (2003) Induction of anti-tumor immunity in mice using a syngeneic endothelial cell vaccine. Anticancer Res 23: 1165-1172.

44. Schraa AJ, Everts M, Kok RJ, Asgeirsdottir SA, Meijer DK, et al. (2002) Development of vasculature targeting strategies for the treatment of cancer and chronic inflammatory diseases. Biotechnol Annu Rev 8: 133-165.

45. Shaheen RM, Ahmad SA, Liu W, Reinmuth N, Jung YD, et al. (2001) Inhibited growth of colon cancer carcinomatosis by antibodies to vascular endothelial and epidermal growth factor receptors. Br J Cancer 85: 584-589.

46. Shreeniwas R, Ogawa S, Cozzolino F, Torcia G, Braunstein N, et al. (1991) Macrovascular and microvascular endothelium during long-term hypoxia: alterations in cell growth, monolayer permeability, and cell surface coagulant properties. J Cell Physiol 146: 8-17.

47. St Croix B, Rago C, Velculescu V, Traverso G, Romans KE, et al. (2000) Genes expressed in human tumor endothelium. Science 289: 1197-1202.

48. Swerlick RA, Lee KH, Li LJ, Sepp NT, Caughman SW, et al. (1992a) Regulation of vascular cell adhesion molecule 1 on human dermal microvascular endothelial cells. J Immunol 149: 698-705.

49. Swerlick RA, Lee KH, Wick TM, Lawley TJ (1992b) Human dermal microvascular endothelial but not human umbilical vein endothelial cells express CD36 in vivo and in vitro. J Immunol 148: 78-83.

50. Thompson PL, Dessureault S (2007) Immune-Mediated Diseases From Theory to Therapy. Springer, New York, 345-355.

51. Wei YQ, Wang QR, Zhao X, Yang L, Tian L, et al. (2000) Immunotherapy of tumors with xenogeneic endothelial cells as a vaccine. Nat Med 6: 1160-1166. 